rev.relac.int.estrateg.segur.7(2):131-155,2012

\title{
LA EFECTIVIDAD DE LA PARTICIPACIÓN DESDE LA EXPERIENCIA DE LAS INSTANCIAS DELIBERATIVAS LOCALES EN BOGOTÁ*
}

\author{
Bibiana Marcela Rueda Rodríguez**
}

\section{RESUMEN}

En este artículo se pretende hacer un análisis de las principales instancias de participación ciudadana en el nivel local en la ciudad de Bogotá, a partir de la noción de efectividad de la participación, entendida como la posibilidad de control sobre la agenda y de control sobre los procesos de toma de decisiones.

Palabras clave: Democracia Participativa, participación ciudadana, efectividad de la participación, niveles de participación.

* Este artículo es parte de la investigación titulada "La participación ciudadana en Bogotá, 2005-2010" realizado durante el año 2011, en el Programa de Relaciones Internacionales y Estudios Políticos de la Universidad Militar Nueva Granada.

** Magister en Ciencia Política. Politológa y magister en Ciencia Política. Docente del pregrado de Ciencia Política y Gobierno de la Universidad Jorge Tadeo Lozano.

Correo electrónico: bibiana.rueda@utadeo.edu.co -bm_rueda@yahoo.es 


\title{
THE EFFECTIVENESS OF PARTICIPATION FROM THE EXPERIENCE OF LOCAL DELIBERATIVE MECHANISMS IN BOGOTA.
}

\begin{abstract}
This article analyzes the main mechanisms for citizen participation in Bogota, using the concept of participation effectiveness, understood as the possibility of controlling both the agenda and the decision-making processes.
\end{abstract}

Key Words: Participative democracy, citizen participation, participation effectiveness, degrees of participation

\section{A EFICÁCIA DA PARTICIPAÇÃO DA EXPERIÊNCIA DE ÓRGÃOS DELIBERATIVOS LOCAIS EM BOGOTÁ}

\section{RESUMO}

O artigo tem como objetivo analisar as principais instâncias de participação cidadã a nível local na cidade de Bogotá, a partir da noção de eficácia de participação, entendida como a possibilidade de controlar a agenda e os processos de decisão.

Palavras-chave: Democracia participativa, participação cidadã, eficácia da participação, níveis de participação.

\section{INTRODUCCIÓN}

En este artículo pretendemos hacer un análisis de la efectividad de la participación en las principales instancias de participación local de la ciudad de Bogotá, partiendo del marco general de la Democracia Participativa, y con un entendimiento de la participación como intervención, utilizando diferentes herramientas teóricas. El análisis parte de una revisión general de la teoría de la Democracia Participativa, y pasa por la explicación de los modelos de análisis que se usarán en el desarrollo del artículo, para finalmente hacer un análisis de las instancias de participación local de la ciudad de Bogotá a la luz de estos modelos.

\section{LA DEMOCRACIA}

Dentro de las Teorías de la Democracia, podemos identificar un conjunto de definiciones de Democracia, todas ellas diferentes entre sí. Las definiciones van desde aquellas más limitadas 
como las definiciones electorales de la democracia, hasta las definiciones más amplias como la maximalista. Incluso la variedad se multiplica cuando los analistas, con el propósito de dar cuenta con mayor exactitud de la realidad, han empezado a acuñar un sinnúmero de subtipos de democracia para describir las particularidades de los regímenes políticos de naciones en vías de desarroIlo, recientemente descolonizadas o en procesos de consolidación o transición del régimen.

Partiendo de un marco general, la democracia liberal se caracteriza por hundir sus raíces en el republicanismo y el liberalismo. Se alimenta del republicanismo en su variante norteamericana en el principio de la representación política, que se pensó con el fin de elegir a unos representantes idóneos para la tarea de tomar decisiones vinculantes para la sociedad, y deliberar las opiniones públicas en el parlamento. Esta influencia es evidente también en la inclusión de elementos del pensamiento de Montesquieu. La influencia de este autor quedó plasmada en los diseños institucionales de las democracias occidentales fundamentados en un modelo de separación de poderes, que impidiera la concentración del poder político dentro del mismo Estado, y como un mecanismo que permitiera que los poderes mismos del Estado se hicieran contrapeso entre sí y se equilibraran (Baños, 2006).

Las raíces liberales se manifiestan en el control del poder y la legalidad. Esto se manifiesta en el lugar destacado que ocupa el sistema derechos en la democracia, todos los derechos, pero en particular los derechos políticos. Los derechos del individuo igualmente se constituyen en una forma de control del poder político, en la medida en que constituyen un límite a la influencia del poder del Estado, y se convierten también en un instrumento que puede hacerse efectivo cuando este poder irrumpe y viola de alguna manera los derechos naturales de los individuos (Baños, 2006). Así mismo, los derechos de expresión y asociación facilitan ese control frente al abuso del poder mediante la denuncia y la movilización. Y finalmente el derecho al voto permite a los ciudadanos expresar sus preferencias políticas al elegir o no a sus representantes.

Los estudios sobre democracia han hecho énfasis en mayor o menor medida en estos elementos de la democracia y es posible encontrar un gran número de definiciones diferentes. Collier y Levitsky (1996) hacen un gran esfuerzo clasificando las definiciones que han orientado los estudios más destacados en la materia y han clasificado estas definiciones en categorías. Cada categoría se diferencia de la otra por incluir un mayor o menor número de condiciones, que se consideran fundamentales para poder catalogar a un régimen político como una democracia. Según estos autores las definiciones de democracia se podrían clasificar en: electorales, de mínimo procedimental, de mínimo procedimental expandido, concepciones prototipo de democracias industriales establecidas, y definiciones maximalistas de la democracia.

Las definiciones electorales son aquellas que conciben la democracia como un régimen en el cual se adelantan elecciones en las que los ciudadanos tienen derecho al sufragio universal y no existe fraude masivo identificado. La concepción procedimental en general hace énfasis en los procedimientos democráticos, y no se fija en políticas o resultados que pueden ser esperados de 
un régimen democrático. En la versión de mínimo procedimental encontramos definiciones que tienen en cuenta la menor cantidad posible de atributos que permitan concebir una democracia, como son el desarrollo de unas elecciones competitivas, pero además la existencia de derechos y libertades básicas, libertad de expresión, reunión y asociación; autores como O’Donnel, Mainwaring, Linz, entre otros, son exponentes de este tipo de concepción. La versión ampliada procedimental contempla estas mismas características pero incluye la condición de que los gobiernos elegidos tengan el poder efectivo de gobernar.

Las concepciones prototipo de las democracias industriales establecidas exponen todas estas condiciones, pero incluyen características económicas y sociales asociadas a las democracias industriales. Finalmente, la concepción maximalista de la democracia incluye definiciones que no mencionan específicamente los elementos anteriores, sino que enfatizan en la presencia de igualdad socioeconómica, y altos niveles de participación popular en las instituciones políticas, económicas y sociales (Collier y Levitsky, 1996)

Con todo esto, y a pesar de la variedad de definiciones, encontramos que todas ellas comparten un elemento común: la elección de representantes políticos mediante la competencia electoral, y la existencia del sufragio universal. Como consecuencia la democracia moderna se concibe esencialmente como democracia representativa, haciendo de la representación uno de los elementos más importantes para el buen funcionamiento de una democracia.

Así, sin importar cuál sea la teoría de la democracia que se adopte, o la concepción que se escoja, comparten unos supuestos comunes. Según Held (1991, p. 361), el principal supuesto de la democracia liberal durante el siglo XIX y XX ha sido "una relación «simétrica〉 y «congruente> entre los que adoptan las decisiones y los receptores de las decisiones políticas". Es decir, se asume que hay una coherencia entre las decisiones que toman los representantes y las necesidades o deseos de los ciudadanos.

La democracia representativa se entiende como un régimen político en el cual el ejercicio del derecho a participar en la toma de decisiones colectivas obligatorias, que tiene cada individuo miembro de la comunidad política, es delegado a un representante con responsabilidad política para que en su nombre ejerza ese derecho. El individuo, así, está atado a unas expectativas altas respecto al desempeño de los representantes y los gobernantes, y a unos ideales que muchas veces difieren de lo que ocurre en la cotidianidad de nuestros países.

En particular, han surgido críticas tanto desde la derecha como desde la izquierda dirigidas a este punto, cuestionando la supuesta simetría y congruencia entre representantes y representados que postula el modelo teórico liberal, ya que se considera que la simetría es insuficiente y tal congruencia no existe. Mientras la derecha exige la potestad de los mercados y la reducción del tamaño del Estado, la izquierda aboga por mayor participación directa de los ciudadanos en las instituciones más importantes de la sociedad (Held, 1991). 
Cada vez es más evidente cómo los regímenes democráticos representativos han enfrentado un conjunto de desafíos que han debilitado el vínculo de representación política que los fundamenta, y que ha hecho que algunos incluso reconozcan abiertamente que la Democracia Representativa está en crisis.

En la historia política reciente de América Latina han venido desarrollándose hechos que indican que enfrentamos una crisis de representatividad, entendiendo la representación política como la relación por la cual los votantes autorizan a los representantes para gobernar. La inestabilidad política de algunos países de la región es evidencia de ello: a partir de 1990 países cómo Perú, Venezuela, Ecuador y Honduras se han enfrentado a intentos más o menos exitosos de golpes de Estado, liderados por diferentes sectores que tienen algo en común: cuestionamientos e inconformidad frente al desempeño de sus gobernantes.

Al respecto, Mainwaring y Bejarano (2006) operacionalizan la crisis de representación democrática en dos niveles: subjetivo y comportamental. En el primero, el subjetivo, la crisis se manifiesta en que los ciudadanos no confían, o no confieren legitimidad a los agentes de representación democrática. En el segundo, el comportamental, la crisis se evidencia en la volatilidad electoral, el colapso de los sistemas de partidos, la aparición de candidatos presidenciales outsider, y baja participación electoral'.

\section{LA DEMOCRACIA PARTICIPATIVA}

La democracia participativa se encuentra en el espectro teórico de la democracia en un intermedio entre la democracia representativa y la democracia directa, caracterizada la primera por la representación política y la segunda por la ausencia de esta. Es un modelo de democracia que tomó fuerza en los años sesenta y que se caracteriza por el énfasis en la participación política.

Este modelo de democracia participativa aparece en contraposición a las concepciones de la democracia que predominaron durante los años cuarenta, lideradas entre otros por la obra Capitalismo, Socialismo y democracia, publicada en 1942, de Joseph Schumpeter. Esta es una

1. Son varios los problemas asociados a la representación política en estos países; sin embargo las explicaciones a la crisis de representación se han agrupado principalmente en tres ejes: 1) el papel de las instituciones que moldean el sistema de partidos, 2) el papel que un mal desempeño de los Estados podría tener en la crisis de representación -que se manifiesta, entre otros, en la desconfianza, la apatía y la deslegitimación de los gobiernos-, y 3) el papel que los medios de comunicación juegan en la construcción de una identidad particular y una imagen negativa de los políticos y de los partidos. Sin embargo, no hay un acuerdo o respuesta final a la pregunta por las causas de la crisis de representación (Mainwaring y Bejarano (2006). 
concepción instrumental y elitista de la democracia, que asemeja la vida política al mercado, entendiéndola como un modelo competitivo en el cual entran en competencia propuestas políticas y se compite por los votos de los electores. Este modelo elitista competitivo fue la base del modelo pluralista clásico norteamericano expuesto por autores como Dahl y Lazerfeld (Vergara, 1998).

Existe un consenso generalizado en que las obras de Carole Pateman (1970), C.B. Macpherson (2003), y Nikos Poulantzas (1986), aportaron los elementos fundamentales de la teoría participativa de la democracia. Estos autores plantearon los puntos centrales del modelo que cuestiona la idea del individuo libre e igual de la teoría liberal, en la medida en que no encuentra correspondencia entre los planteamientos teóricos y la realidad. El modelo hace énfasis en la necesidad del reconocimiento real de los derechos de los individuos, sin distinción de clase o género, ya que de no ser así no se verán reflejados en la vida cotidiana. Igualmente, plantea cómo las asimetrías de poder, evidentes en las diferencias de recursos y oportunidades de los individuos, limitan su participación efectiva en la vida política (Held, 1991).

Sobre este punto, se discute el papel del Estado como un ente separado de la sociedad, en la medida en que si no está inmerso en las prácticas de la vida cotidiana, y solo tiene un papel de juez o mediador, se convierte en un reproductor de las desigualdades que en ella se presenten (Held 1991). Nikos Polantzas, (1980, citado por Held 1991), por ejemplo, plantea que el Estado debe ser democratizado, facilitando el acceso de los ciudadanos al parlamento, la burocracia y los partidos; y que, finalmente, se debe dinamizar la lucha a nivel local a través de grupos de presión y movimientos. De esta manera, tanto el Estado como la sociedad se democratizan, quedando sujetos a mecanismos que garanticen su responsabilidad. Por esa misma vía, se plantea la necesidad de una participación más directa y permanente de los ciudadanos en la regulación de la sociedad y el Estado, buscando un control mucho más efectivo de parte de la ciudadanía.

El modelo participativo de la democracia no niega la existencia de los mecanismos representativos, ya que los autores son conscientes de la complejidad de las sociedades modernas; lo que pretenden es más bien una coexistencia de estos mecanismos con los de la democracia directa, que permita una participación más activa de los ciudadanos (Vergara, 1998).

La pretensión es incluso que se democraticen los diferentes espacios de la vida cotidiana de las personas. Se busca estimular la participación generando confianza en su efectividad, para finalmente lograr un mayor grado de satisfacción de la ciudadanía con sus gobiernos, un mayor grado de legitimidad, obediencia y respaldo a las decisiones políticas. También se pretende una mejor calidad de vida, en la cual el autodesarrollo como derecho igual de todos los ciudadanos se logre a través de una sociedad participativa, con una ciudadanía preocupada por los problemas colectivos, e interesada en el proceso de gobierno (Held, 1991). 


\section{LA PARTICIPACIÓN}

En el modelo de democracia participativa, el concepto de participación adquiere un contenido diferente del inferido en el modelo liberal. En el modelo liberal la Democracia se ve limitada a un conjunto de reglas para elegir un gobierno (Schumpeter, 1988), o para elegir unas mayorías (Bobbio, 2010). En este sentido se entiende que la participación de los ciudadanos se limita a participar en unas elecciones periódicas, con el fin de elegir a unos gobernantes, y que es fundamentalmente indirecta, es decir que se da a través de unos representantes. Esta caracterización indirecta de la participación se fortalece con la problematización de la viabilidad de la participación individual directa de los ciudadanos en las democracias modernas de gran escala.

En el modelo de democracia participativa, se cuestiona la idea de que la representación agota las posibilidades de participación de los ciudadanos, y que ella misma de cuenta de la diversidad de posiciones socio-culturales de una sociedad específica. También cuestionan la capacidad de la burocracia de tomar decisiones sin contar con la información completa y pertinente proveniente de las comunidades mismas, y manifiesta la preocupación por la representación adecuada de las minorías sociales.

En el contexto del modelo de democracia participativa, la participación tiene un significado mucho más amplio. En contraposición a una concepción netamente indirecta de la participación aparece una noción más directa, la participación como intervención. Esta noción no niega la necesidad de la realización y organización de algunas de las actividades políticas a través de la mediación de representantes, pero sí postula la complementación de los mecanismos representativos, con unos mecanismos que permitan a los ciudadanos un papel mucho más activo en el proceso de toma de decisiones políticas, a través de una participación más directa o de mayor intervención (Held, 1991).

La participación en este contexto de la democracia participativa es, como dice Sartori (1994, p. 74), un "tomar parte personalmente, un tomar parte activo que verdaderamente sea mío, decidido y buscado libremente por mí [...]. Participación es ponerse en movimiento por sí mismo, no ser puesto en movimiento por otros (movilización)". Así, la democracia participativa hace énfasis en la participación política, pero entiende la participación política como algo más que la mera participación electoral, es decir que no limita la participación política al voto simplemente.

En este sentido, se entiende la participación como "una forma de acción individual o colectiva que implica un esfuerzo racional e intencional de un individuo o un grupo en busca de logros específicos - tomar parte en una decisión, por ejemplo - a través de una conducta cooperativa" (Velasquéz \& Gonzalez, 2003, p. 57). Esto implica que la participación tiene variedad de 
campos de acción, que van desde lo electoral, pasando por instancias establecidas dentro del Estado con este fin, y que finalmente pueden darse en espacios no institucionalizados dentro del Estado. Como sugieren autores como Carole Pateman (1970), estos campos de acción se ven en los diversos espacios de la vida cotidiana.

Para Arnstein (1969), la participación es sinónimo de empoderamiento y de redistribución del poder que permite la inclusión de todos los ciudadanos excluidos de los procesos económicos y políticos. Para Arnstein la verdadera participación ocurre cuando el ciudadano tiene el poder real de afectar el resultado de un proceso.

En este sentido, es posible medir de alguna manera lo que podríamos llamar la efectividad de la participación a partir del grado de empoderamiento de los ciudadanos, es decir cuando el ciudadano tiene el poder real de afectar el resultado de un proceso. A mayor grado de empoderamiento se supondría mayor grado de injerencia de la ciudadanía en las decisiones políticas.

Al respecto, Brager y Specht (1973) proponen unos niveles de participación dispuestos como un continuum de participación que va desde un mayor a un menor grado de participación (Tabla 1), describiendo el papel del Estado y los ciudadanos en cada uno de los niveles. Una herramienta como esta nos permitiría medir la efectividad de la participación de diferentes mecanismos de participación, entendida esta como su posibilidad de afectar los resultados de un proceso político y alcanzar objetivos.

Tabla No. 1: Continuum de participación ciudadana

\begin{tabular}{|c|c|c|}
\hline Grado/Nivel & $\begin{array}{c}\text { Rol/actividad } \\
\text { participante }\end{array}$ & \multicolumn{1}{c|}{ Descripción } \\
\hline Elevado & Ejerce control & $\begin{array}{l}\text { La organización se dirige a la comunidad para identificar } \\
\text { un problema y para que tome las decisiones sobre objeti- } \\
\text { vos y medios por sí misma, pero con ayuda y tutela de la } \\
\text { organización en cada fase para ayudar a alcanzar los obje- } \\
\text { tivos. }\end{array}$ \\
\cline { 2 - 3 } & $\begin{array}{l}\text { Ejerce control } \\
\text { por delegación }\end{array}$ & $\begin{array}{l}\text { La organización identifica y presenta el problema a la co- } \\
\text { munidad, define los límites de la participación y pide a la } \\
\text { comunidad tomar ciertas decisiones para ser incorpora- } \\
\text { das a un plan de acción aceptable para todos. }\end{array}$ \\
\hline
\end{tabular}




\begin{tabular}{|c|c|c|}
\hline Grado/Nivel & $\begin{array}{l}\text { Rol/actividad } \\
\text { participante }\end{array}$ & Descripción \\
\hline & $\begin{array}{l}\text { Planificación } \\
\text { conjunta }\end{array}$ & $\begin{array}{l}\text { La organización presenta un plan, sujeto a cambio y abier- } \\
\text { to a la modificación, para adaptarse a las necesidades de } \\
\text { las partes afectadas. Esta dispuesta a hacer ciertos cambios } \\
\text { si estima que hay motivos que lo justifican. }\end{array}$ \\
\hline & Asesor & $\begin{array}{l}\text { La organización presenta un plan e invita al público a apor- } \\
\text { tar propuestas/consejos. Modificará el plan únicamente si } \\
\text { hay motivos muy convincentes que lo justifican. }\end{array}$ \\
\hline Bajo & Consulta & $\begin{array}{l}\text { La organización intenta promover un plan y está buscan- } \\
\text { do apoyo para facilitar su aceptación y legitimación, para } \\
\text { asegurar el cumplimiento administrativo. }\end{array}$ \\
\hline Nulo & $\begin{array}{l}\text { Es receptor de } \\
\text { información }\end{array}$ & $\begin{array}{l}\text { La organización elabora un plan y lo presenta al público. } \\
\text { La comunidad está convocada por razones informativas y } \\
\text { para afianzar su cumplimiento. }\end{array}$ \\
\hline
\end{tabular}

Fuente: Brager y Specht (1973).

El continuum de Brager y Specht (1973) es solo uno de los diferentes modelos de niveles de participación. Existe también el modelo de la "Escalera de la Participación" de Arstein (1969), la Escalera de los niveles de participación de Hambleton y Hogget (1994), el Continuum de la participación ciudadana de Shand y Arnberg (1996), y el Spectrum de participación de la Asociación Internacional para la Participación Pública. Sin embrago, en este artículo usaremos el modelo de Brager y Spech, por considerar que los niveles que plantea son más susceptibles de ser operacionalizados que los de otros modelos.

Por otro lado, es importante notar que la posibilidad real de influir en las decisiones políticas depende del margen de acción que permita el marco normativo existente. A propósito, Stewart (2007) plantea que el proceso de participación ciudadana puede ser visto como un juego en el cual participan, por un lado, un grupo de ciudadanos, y por el otro, de funcionarios públicos, cada uno con preferencias que generalmente son diferentes u opuestas, aunque no siempre. Cada uno de los participantes en este juego, si quiere conseguir sus objetivos, debe lograr adherir el capital político del otro. Los funcionarios necesitan el apoyo de los ciudadanos para aplicar políticas que pueden ser impopulares, y los ciudadanos el apoyo del gobierno para que sus objetivos políticos sean aprobados por la administración. 
Para este autor, el juego de la participación ocurre en dos rondas. En un primer momento, los actores establecen las reglas de juego bajo las cuales la participación se va a llevar a cabo. En un segundo momento, se da la interacción real, bajo las reglas de juego definidas en el primer momento. Así, la definición de las reglas de juego bajo las cuales se adelanta el juego de la participación son una etapa fundamental, pues es allí cuando se definen las posibilidades reales de controlar los resultados del juego mediante: 1) la definición de la agenda y 2) el control en el proceso de toma de decisiones.

No solo el proceso de toma de decisiones es importante en el proceso de la participación, sino que también es fundamental la definición de la agenda; de hecho se considera que es un momento clave del proceso político. Stewart (2007), basándose en los planteamientos de Hasan Ozbekhan (1969, citado en Stewart, 2007), identifica tres niveles de control de la agenda: operacional, estratégico y normativo.

En el nivel operacional se permite solo el intercambio de información; aquí las estrategias y los objetivos políticos ya están definidos, y la actividad de los ciudadanos se limita a la ejecución de tareas y el cumplimiento de calendarios establecidos, con un mínimo margen de acción en la discusión de las tareas y metas establecidas. En el nivel estratégico los objetivos políticos ya están planteados, pero se permite discutir las estrategias para alcanzarlos, por lo general discutiendo y teniendo en cuenta la viabilidad y disponibilidad de recursos. Finalmente, en el nivel normativo, es posible para los ciudadanos discutir los problemas que deben ser abordados, es decir existe la posibilidad de definir metas y estrategias. Este último nivel es el menos restrictivo.

El control en el proceso de toma de decisiones está relacionado con los niveles de participación mencionados anteriormente. En este caso Stewart retoma algunos de los niveles planteados en la escalera de la participación planteada por Arnstein, y clasifica los diferentes mecanismos de participación, en términos del nivel de control en el proceso de toma de decisiones en: informativos, consultivos, y delegativos. Los mecanismos informativos son mecanismos que permiten a los gobiernos comunicar e informar a los ciudadanos sobre las decisiones que se han tomado, y no permiten a los ciudadanos emitir ninguna opinión o retroalimentación sobre el resultado político. Los mecanismos consultivos permiten a la ciudadanía emitir una opinión pero la decisión final es adoptada por el gobierno. Finalmente, los mecanismos delegativos permiten a los ciudadanos un control final del resultado, de la decisión, pero no completo, ya que al gobierno también se le permite participar.

Así, Stewart (2007) elabora una matriz de control en la que cruza estos dos ejes con el fin de clasificar los diferentes mecanismos de participación y dar cuenta del grado de control y efectividad de la participación en términos del control de la agenda y del proceso de toma de decisiones (Gráfico 1). 
Es claro que los ciudadanos preferirán mecanismos que se correspondan a la casilla 3, iii, que les den el mayor control posible sobre la definición de la agenda y la toma de decisiones. Mientras el gobierno seguramente preferirá mecanismos que se ubiquen en la casilla i, 1, que den a los gobiernos mayor control en estos aspectos.

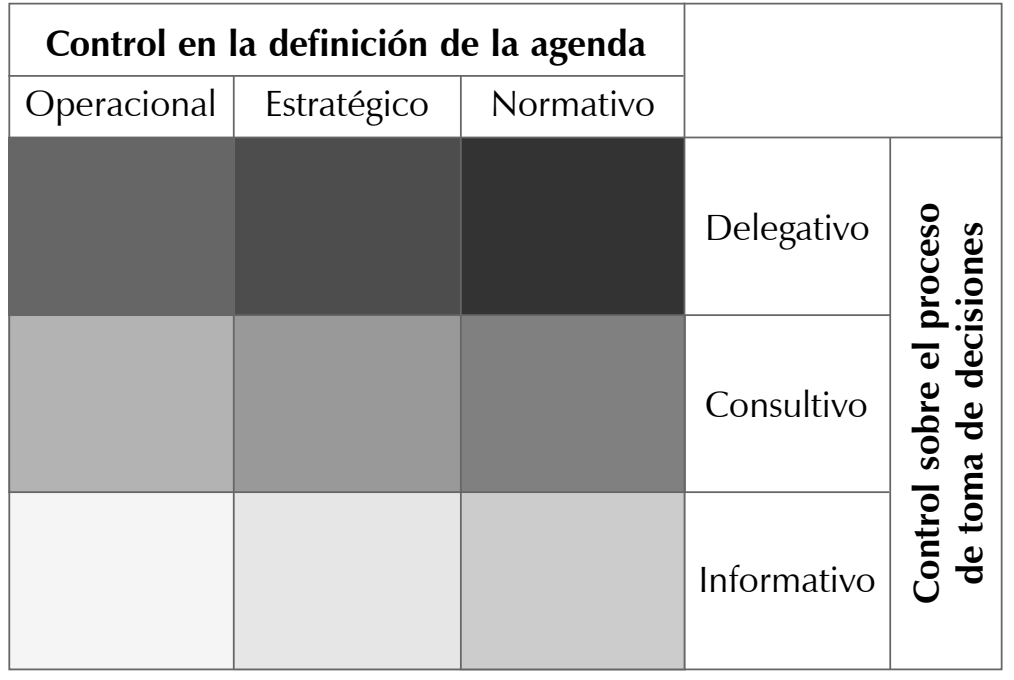

Gráfico No. 1: Control sobre el proceso de toma de decisiones

Fuente: Stewart (2007)

\section{ANÁLISIS DE LAS INSTANCIAS DE PARTICIPACIÓN EN BOGOTÁ SEGÚN LA MATRIZ DE BRAGER Y SPECHT Y LOS NIVELES DE PARTICIPACIÓN DE STEWART.}

En este artículo se analizarán las instancias de participación ciudadana local que según el Instituto Distrital de Participación Ciudadana (IDPAC, 2009) son las más utilizadas por la población en las localidades de Bogotá, a la luz de los diferentes niveles de participación planteados por Brager y Specht (1973) y por Stewart (2007), con el fin de determinar el grado de efectividad de la participación en términos del nivel de participación y control según plantean estos autores.

La delimitación de los mecanismos a aquellos identificados por el IDPAC como los más usados no quiere decir que son las únicas instancias que se encuentran en la oferta institucional de la ciudad, pero sí que son las que están siendo efectivamente utilizadas por los ciudadanos y las que están canalizando la actividad participativa de la ciudad.

Luego de revisar cada una de las instancias de participación, algunas distritales y otras locales específicamente, podemos clasificarlas según sus funciones y su composición, en cada uno de 
los ejes, ya sea el control sobre el proceso de toma de decisiones, o el control sobre la definición de la agenda, así como en el nivel de participación al que pertenecen.

Control en la Definición de la agenda

En lo que respecta al control en la definición de la agenda hemos clasificado como operacionales a las siguientes instancias: la Comisión Ambiental Local (Decreto 697 de 1993/Decreto 625 de 2007/Decreto 575 de 2011), los Consejos Distritales y Locales de Política Social (Decreto 093 de 2004/Decreto 460 de 2008), los Comités de Desarrollo y Control Social de los Servicios Públicos (Acuerdo 21 de 2001), el Comité Local de Emergencias (Decreto 332 de 2004), los Consejos Distritales y Locales de Juventud (Acuerdo 033 de 2001), y las Veedurías Ciudadanas (Acuerdo 142 de 2005).

En el análisis de la Comisión Ambiental Local es importante considerar que de los 19 miembros que la integran, solo 7 son representantes directos de la sociedad civil organizada, mientras los demás corresponden a representantes de organizaciones públicas y un representante de la JAL. Aunque se destaca que la participación social es amplia, la mayoría claramente la compone el gobierno. En general la función de la Comisión Ambiental es apoyar la elaboración e implementación de políticas públicas ambientales, y apoyar y gestionar iniciativas y propuestas ambientales comunitarias con el sector público y privado, de orden local, distrital, nacional e internacional. Debido a la composición de la instancia, la injerencia de la ciudadanía organizada se ve disminuida. Es una instancia que facilita el proceso de toma de decisiones de la administración en la medida en que ofrece insumos en la priorización de temas, pero no es decisivo.

El Consejo Distrital de Política Social está compuesto por veintidós representantes de organizaciones públicas, y 24 de la sociedad civil, de los cuales 10 son representantes de otros consejos con composiciones mixtas. Las funciones del consejo distrital son: asesorar y apoyar en el proceso de construcción de la Política Social del Distrito, recomendar los lineamientos de la Política Social, preparar y presentar a las instancias pertinentes conceptos y recomendaciones sobre los planes, programas y proyectos de la Política Social Distrital, así como de los proyectos de leyes, acuerdos $\mathrm{u}$ otras regulaciones relativas a la misma. Sus funciones son principalmente efectuar las recomendaciones y solicitudes que considere oportunas en procura de alcanzar los objetivos propuestos por el Consejo Distrital de Política Social, y realizar el seguimiento a la aplicación de las recomendaciones emitidas. Su composición no está claramente diferenciada en la norma, y se entiende que deben conformarse según la conformación del Consejo Distrital. Si bien estos Consejos emiten informes valiosos para la construcción de las políticas Distritales de Salud, no son quienes las definen.

Los Comités de Desarrollo y Control Social de los Servicios Públicos son instancias que se conforman por iniciativa de los ciudadanos; de ellos pueden hacer parte todos aquellos usuarios, suscriptores o suscriptores potenciales del servicio público. Entre sus funciones se cuentan controlar la prestación de los servicios públicos domiciliarios, proponer a las empresas planes y 
programas que resuelvan las deficiencias en la prestación de los servicios, y solicitar la modificación o reforma de las decisiones que se adopten en materia de Estratificación. Sin embargo, es otra instancia que se limita a emitir recomendaciones sobre la prestación del servicio.

El Comité Local de Emergencias es un comité compuesto por: el Alcalde local, un representante de la Junta Administradora Local designado por ésta, un delegado de la Dirección de Prevención y Atención de Emergencias - DPAE -, el Gerente de la Empresa Social del Estado de la jurisdicción, el gerente del Centro Operativo local del DABS, el presidente de la asociación de juntas de acción comunal de la localidad, ASOJUNTAS, el delegado de las Juntas de Defensa Civil de la localidad, el coordinador de la Oficina de Planeación de la Alcaldía local, el delegado del DAMA, el coordinador del Centro Administrativo de Educación Local, CADEL, el delegado del centro zonal del ICBF, el comandante de la estación de bomberos de la localidad, el comandante de la estación de policía de su jurisdicción, el comandante de la unidad militar que tenga jurisdicción en la localidad, los delegados de otras entidades públicas o privadas que por decisión del propio Comité deban participar como miembros del mismo. Es claro cómo la participación de la sociedad civil en la composición de este comité es muy limitada, destacándose en este caso el presidente de ASOJUNTAS.

En este sentido el Comité Local de Emergencias, compuesta en un 99\% por representantes del sector público, tiene como funciones: conceptuar sobre el proyecto del Plan Local de Prevención y Atención de Emergencias antes de su adopción por el correspondiente alcalde local; realizar labores de coordinación, apoyo, asesoría y distribución y asignación de responsabilidades para la ejecución del Plan Local de Prevención. Es una instancia con escasa participación de la sociedad civil, y que además se limita a conceptuar, asesorar y ejecutar el Plan Local de Prevención.

Los Consejos Distritales y Locales de Juventud están conformados por miembros electos de listas presentadas directamente por los jóvenes, y de candidatos propuestos por organizaciones juveniles; también hay asiento para representantes de las minorías presentes en las localidades. Sus funciones son: actuar como instancia de interlocución y consulta ante la administración y las entidades públicas del orden distrital, local, nacional, territorial y ante las organizaciones privadas no gubernamentales del ámbito nacional e internacional en los temas concernientes a la juventud; proponer a las respectivas autoridades planes y programas para el cabal desarrollo de las disposiciones de las normas relativas a la juventud, y concertar su inclusión en los correspondientes planes de desarrollo; cogestionar planes, programas y recursos dirigidos a la juventud que contribuyan al desarrollo de los propósitos de la Ley 375 de 1997; establecer estrategias y procedimientos para que los jóvenes participen en el diseño, evaluación y veeduría de políticas, planes, programas y proyectos de desarrollo dirigidos a la juventud; y trabajar en coordinación con la instancia definida por la Administración Distrital para construir y desarrollar la política de juventud.

Si bien es una instancia compuesta en su totalidad por jóvenes de las localidades y representantes de la sociedad civil organizada, es una instancia de consulta, que propone y gestiona iniciativas, y da insumos a la administración que puede usar o no para la construcción de la política de 
juventud. Las recomendaciones de la instancia no son de carácter obligante para la administración, pero su presencia sí es importante como una instancia legitimadora, que apoya la implementación de las políticas públicas de juventud, y promueve la participación de los jóvenes en las diferentes instancias locales.

En el caso de las veedurías ciudadanas, a estas las pueden conformar todos los ciudadanos en forma plural, a través de organizaciones civiles como organizaciones comunitarias, profesionales, juveniles, sindicales, o no gubernamentales, y que se conformen e inscriban según la ley para ese fin. Entre sus funciones se encuentran: vigilar los procesos de planeación, para que conforme a la Constitución y la ley se dé participación a la comunidad; vigilar que en la asignación de los presupuestos se prevean prioritariamente la solución de necesidades básicas insatisfechas, según criterios de celeridad, equidad y eficacia; vigilar que el proceso de contratación se realice de acuerdo con los criterios legales; y vigilar y fiscalizar la ejecución y calidad técnica de las obras, programas e inversiones en el correspondiente nivel territorial. Estas veedurías ejercen una actividad dirigida al control de las acciones públicas, pero no intervienen en la definición de estrategias y objetivos políticos de forma decisiva, sino que pretenden influir mediante la vigilancia y la presentación de recomendaciones.

Pueden ser clasificados en el nivel estratégico el Consejo Territorial de Planeación Distrital (Acuerdo 12 de 1994), el Consejo de Planeación Local (Acuerdo 13 de 2000), el Consejo Local y Distrital de personas con discapacidad (Acuerdo 22 de 1999/Acuerdo 137 de 2004), y los Consejos Distritales y Locales de Cultura (Decreto 221 de 2002/Decreto 627 de 2007).

En el caso de los Consejos de planeación, tienen entre sus competencias la discusión de los planes de desarrollo local o distrital, y su función es promover la discusión de ese plan ya elaborado y formular recomendaciones al mismo, con base en las discusiones que se dieron en los encuentros ciudadanos. No tienen la posibilidad de incidir en la decisión pero sí emiten su opinión sobre el plan; sin embargo, no es obligación de la alcaldía incluir esas recomendaciones.

El Consejo Local de Personas con Discapacidad está conformado por nueve representantes de la administración y seis representantes de las personas con limitación y/o discapacidad (física, mental, cognitiva, auditiva, visual y discapacidad múltiple). Sus funciones son, entre otras, las siguientes: promover la construcción de la política y plan local de discapacidad para que sean armónicos con el Plan Distrital de Discapacidad y el Plan de Desarrollo Local en materias relacionadas con las personas en condición de discapacidad; asesorar a las autoridades locales en la formulación de programas, planes y proyectos a favor de las personas en condición de discapacidad de la localidad; y ejercer veeduría y control social sobre el desarrollo de los programas, planes y proyectos de la localidad en pro de las personas en condición de discapacidad, de acuerdo a las directrices del Plan Distrital de Discapacidad el Plan de Desarrollo Local y Distrital. Es una instancia que participa en la construcción de la política de discapacidad local, en el marco de la política distrital, y tiene un amplio margen propositivo. 
Así mismo, el Consejo Distrital de Personas con Discapacidad está conformado por once representantes de la administración y seis representantes de las personas con limitación y/o discapacidad (física, mental, cognitiva, auditiva, visual y discapacidad múltiple). Dentro de sus funciones está: asesorar la formulación de las políticas en prevención; cuidados en salud y sicológicos; habilitación, rehabilitación, educación y orientación; integración laboral y de garantías de los derechos fundamentales económicos, culturales y sociales de las personas en condición de discapacidad del Distrito Capital, y gestionar ante las autoridades distritales y sus diferentes instancias y espacios de planeación para que puedan hacer parte del Plan de Desarrollo Distrital y en su respectivo presupuesto de conformidad con las disposiciones legales y reglamentarias vigentes; evaluar y hacer las recomendaciones que sean pertinentes para la formulación y el cumplimiento de los programas y proyectos contemplados en el Plan Distrital de Discapacidad del Distrito Capital para el funcionamiento de la Red Territorial; $y$ proponer mecanismos de vigilancia para verificar el cumplimiento de las políticas, programas y proyectos contemplados en el Plan Distrital de Discapacidad del Distrito Capital. Este Consejo se limita a la asesoría en la elaboración de políticas, y a gestionar espacios para participar en las instancias distritales, y hacer recomendaciones para el Plan de Desarrollo distrital. Son funciones del Comité Técnico del Consejo Distrital consolidar el plan de acción por líneas del Plan Territorial de Discapacidad y coordinar su ejecución en las localidades. En ese sentido, claramente, aunque no puede definir los objetivos, sí las estrategias para alcanzarlos, teniendo en cuenta, como nos dice la teoría, la viabilidad y los recursos.

Los Consejos Distritales y Locales de Cultura son instancias con una conformación mixta, que incluye representantes de la administración y representantes de la sociedad civil y de otras instancias de participación. Aunque no definen los objetivos de cultura en la ciudad, sí asesoran la definición de las políticas puntuales que se desarrollaran para llevar a cabo esos objetivos. Son instancias asesoras y consultoras, que ejercen control, y que en el caso de los Consejos Locales, por ejemplo, presentan y gestionan ante las autoridades e instancias de planeación vigentes, el documento de políticas culturales elaborado por el Consejo Local de Cultura para la formulación y ejecución de los Planes de Desarrollo Local correspondientes; así que sí tienen injerencia en las estrategias adoptadas para ejecutar el plan de desarrollo local o Distrital.

Finalmente, en el nivel normativo encontramos a las Asociaciones de Usuarios de Salud y los Comités de Participación Comunitaria en Salud (Decreto 1757 de 1994), y al Consejo Local de Seguridad. En este nivel se espera que sea posible para los ciudadanos discutir los problemas que deben ser abordados, es decir, la posibilidad de definir metas y estrategias.

Las Asociaciones de los Usuarios de Salud, además de asesorar a sus afiliados, tienen como función participar en las Juntas Directivas de las empresas promotoras de salud e instituciones prestatarias de servicios de salud, sean públicas o mixtas, para proponer y concertar las medidas necesarias para mantener y mejorar la calidad de los servicios y la atención al usuario. En el caso de las privadas, se podrá participar, conforme a lo que dispongan las disposiciones legales sobre la materia. 
Los Comités de Participación Comunitaria en Salud están conformados por autoridades locales y representantes de organizaciones sociales y aquellas que se relacionen con la salud, además de intervenir en las actividades de planeación, asignación de recursos y vigilancia y control del gasto en todo lo atinente al Sistema General de Seguridad Social en Salud en su jurisdicción respectiva; participar en el proceso de diagnóstico, programación control y evaluación de los servicios de salud; presentar planes, programas y prioridades en salud a la junta directiva del organismo o entidad de salud, o a quien haga sus veces; también tienen la función de elegir por y entre sus integrantes, un representante ante la Junta Directiva de la Empresa Social del Estado de la respectiva entidad territorial, conforme las disposiciones legales sobre la materia.

La ley permite a estas dos instancias elegir representantes como delegados ante las juntas directivas de las empresas promotoras de salud e instituciones prestatarias de servicios de salud, y ante la Junta Directiva de la Empresa Social del Estado de la respectiva entidad territorial. En esa medida es claro que, aunque su participación se limita a un delegado, hacen a través de éste parte de instancias que sí tienen la capacidad de decidir y de influir en los objetivos y las estrategias políticas de ciertas empresas, públicas y privadas. Es por eso que se clasifican en el nivel normativo.

En el caso de los Consejos Locales de Seguridad, estos se encargan de formular, aprobar, tramitar y remitir a la Secretaría de Gobierno, para ejecución, evaluación y seguimiento, los Planes Integrales de Seguridad para la Localidad, fijando, objetivos y estrategias. Sin embargo, cabe anotar que su composición no refleja en mucho la participación directa de la ciudadanía, pues en su gran mayoría está compuesto por representantes de la administración, y tan solo hay un miembro que es delegado por otra instancia similar, que es el delegado del Consejo Local de Política Social.

\section{Control sobre el proceso de toma de decisiones}

En lo que respecta a la participación en la toma de decisiones existen tres posibles tipos de mecanismos: informativos, consultivos, y delegativos. Podemos considerar como instancias consultivas a varias de las instancias anteriormente mencionadas: el Consejo Territorial de Planeación Distrital, el Consejo de Planeación Local, los Consejos Distritales y Locales de Cultura, la Comisión Ambiental Local, los Consejos Locales y Distritales de Política Social, los Comités de Desarrollo y Control Social de los Servicios Públicos, el Comité Local de Emergencias, los Consejos Distritales y Locales de Juventud, el Consejo Local y el Distrital de personas con discapacidad, y las Veedurías Ciudadanas. Son consultivas porque son instancias que -como queda establecido en sus funciones- permiten a la ciudadanía emitir una opinión sobre los temas en cuestión, pero la decisión final siempre es adoptada por el gobierno.

Por otro lado, son instancias delegativas las Asociaciones de Usuarios de Salud y los Comités de Participación Comunitaria en Salud, y los Consejos Locales de Seguridad. Son delegativos porque permiten a los ciudadanos un control final del resultado, de la decisión, pero no completo, ya que 
el gobierno también participa. Aunque en algunos casos esa participación ciudadana es como minoría, se trata de una participación en la cual la opinión no es solo voz sino también voto.

Teniendo esto en cuenta, encontramos que en lo que respecta a la matriz de Stewart (2007), en el nivel de control de la agenda, de las quince instancias analizadas siete de ellas corresponden a un nivel de control de tipo operacional, cinco en el nivel estratégico, y tres al normativo; en el nivel de control sobre el proceso de toma de decisiones, doce corresponden al nivel consultivo, y tres al delegativo. Sin embargo es de la combinación de estos dos criterios que podemos clasificar con más claridad los mecanismos en la matriz, con el fin de identificar realmente la efectividad de la participación en términos de la mayor intervención de los ciudadanos en la toma de decisiones, entendida en esta matriz como un mayor control sobre la agenda y proceso de toma de decisiones, ambos elementos claves en la efectividad de la participación.

Tabla 2: Instancias de Participación Local en Bogotá en la Matriz de Stewart (2007)

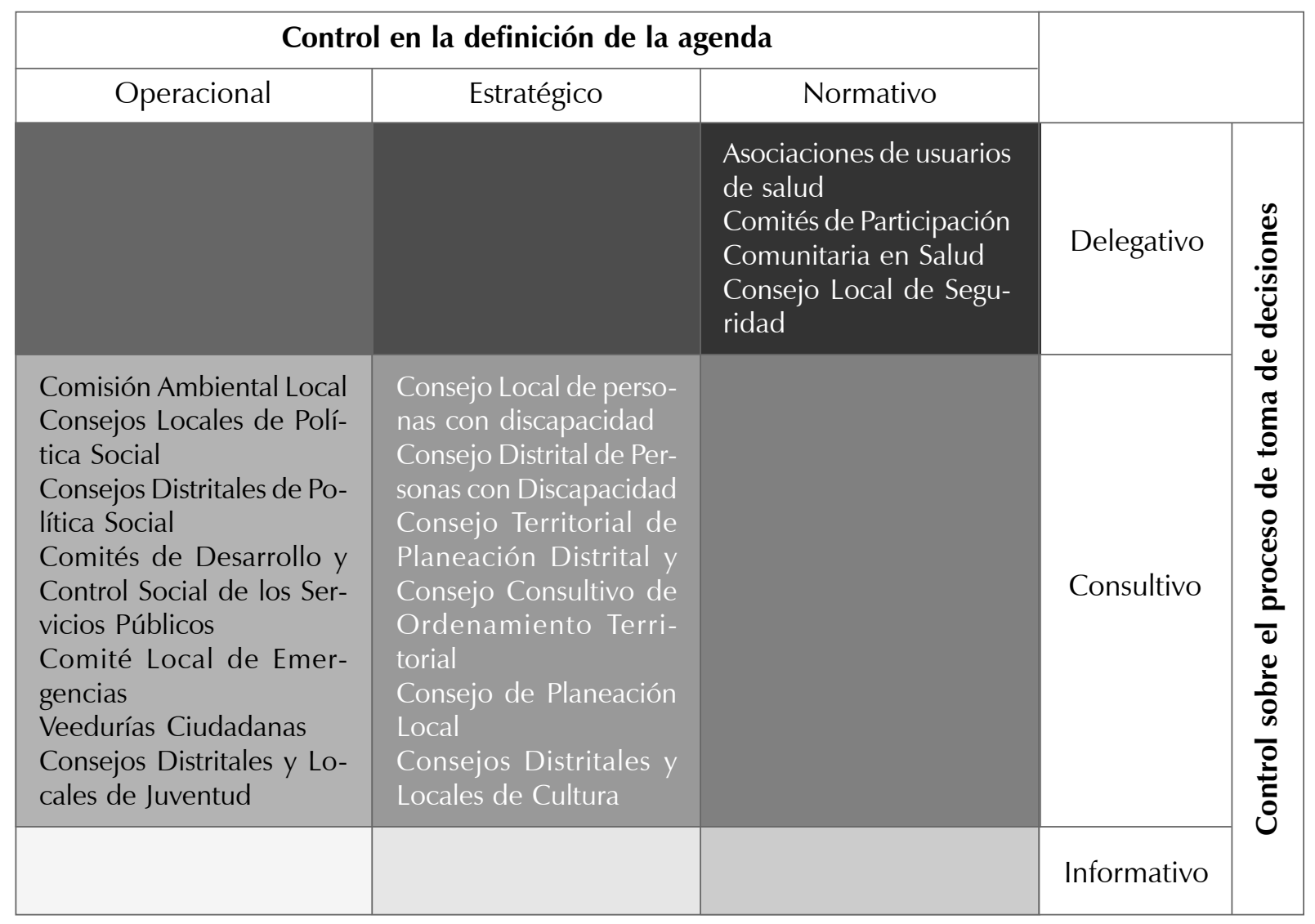

Fuente: Elaboración Propia. 
Lo que nos permite observar la matriz de la Tabla 2 es la distribución de los mecanismos de participación local estudiados de Bogotá, según el nivel de control de la agenda y de control sobre el proceso de toma de decisiones que tienen los ciudadanos en cada uno de ellos. En este sentido, vale la pena destacar la importancia de los dos tipos de control en el ejercicio de la participación, más si entendemos la participación como la entendemos en este artículo, esto es, como intervención.

Como señala Stewart (2007), dentro del proceso de participación no solo es importante poder tener injerencia en las decisiones que se toman, sino también, y casi más importante, poder tener injerencia sobre los temas que se van a discutir. De ahí la importancia del control sobre la agenda que tienen los mecanismos de participación. Por otro lado, es importante la injerencia sobre la decisión misma, ya que la participación entendida como intervención, en la cual haya una redistribución del poder de decisión, implica el mayor control posible de los procesos de toma de decisiones.

De la combinación de los niveles que en uno y otro criterio propone Stewart (2007), se dan diferentes posibles combinaciones de niveles de efectividad de la participación, que van desde mecanismos con niveles ideales de control de la agenda (normativo) y de los procesos de toma de decisiones (delegativo), hasta los menos deseables de uno (operacional) y otro (informativo); pasando por niveles intermedios, que aunque no son los ideales, representan una mejor posición que los menos deseables (en esa categoría entran el nivel estratégico y el consultivo).

Una participación efectiva nos haría desear mecanismos de participación ubicados en el vértice derecho superior de la matriz. En este sentido, de la combinación de estos niveles en la matriz, podríamos establecer unos niveles de efectividad de la participación, asumiendo que es más efectiva en la medida en que mayor control sobre la agenda y los procesos de toma de decisiones ejerza.

Teniendo esto en cuenta podríamos hablar de cinco niveles de efectividad de la participación:

\section{BAJO:}

Operacional-informativo: en este nivel no existe posibilidad de controlar la agenda, y las estrategias y los objetivos políticos están previamente definidos; tampoco existe injerencia sobre los procesos de toma de decisiones, ya que se permite solo el intercambio de información.

\section{MEDIO BAJO:}

Operacional-consultivo: en este nivel no existe posibilidad de controlar la agenda, y las estrategias y los objetivos políticos están previamente definidos; tampoco existe injerencia sobre los 
procesos de toma de decisiones, aunque se permite a la ciudadanía emitir una opinión. Sin embargo, la decisión final es adoptada por el gobierno.

Estratégico-informativo: en este nivel no existe posibilidad de controlar la agenda; sin embargo, aunque los objetivos políticos ya están planteados, se permite a los ciudadanos discutir las estrategias para alcanzarlos, teniendo en cuenta la viabilidad y disponibilidad; y no existe injerencia sobre los procesos de toma de decisiones, ya que se permite solo el intercambio de información.

\section{MEDIO:}

Operacional-delegativo: en este nivel no existe posibilidad de controlar la agenda, y las estrategias y los objetivos políticos están previamente definidos; sin embargo, sí tienen injerencia sobre los procesos de toma de decisiones, ya que permiten a los ciudadanos un control final del resultado, de la decisión, pero no completo, ya que al gobierno también se le permite participar.

Estratégico-consultivo: en este nivel no existe posibilidad de controlar la agenda; sin embargo, aunque los objetivos políticos ya están planteados, se permite a los ciudadanos discutir las estrategias para alcanzarlos, teniendo en cuenta la viabilidad y disponibilidad; tampoco existe injerencia sobre los procesos de toma de decisiones, aunque se permite a la ciudadanía emitir una opinión. Sin embargo, la decisión final es adoptada por el gobierno.

Normativo-informativo: en este nivel, los ciudadanos sí pueden controlar la agenda, pueden discutir los problemas que deben ser abordados, es decir, existe la posibilidad de definir metas y estrategias; sin embargo, en el proceso de toma de decisiones, su injerencia es nula, pues aunque participen en la definición de los temas a discutir, no tienen injerencia en el proceso de toma de decisiones, y solo se permite el intercambio de información.

\section{MEDIO ALTO:}

Estratégico-delegativo: en este nivel no existe posibilidad de controlar la agenda; sin embargo, aunque los objetivos políticos ya están planteados, se permite a los ciudadanos discutir las estrategias para alcanzarlos, teniendo en cuenta la viabilidad y disponibilidad; sin embargo, sí tienen injerencia sobre los procesos de toma de decisiones, ya que permiten a los ciudadanos un control final del resultado, de la decisión, pero no completo, ya que al gobierno también se le permite participar.

Normativo-consultivo: en este nivel, los ciudadanos sí pueden controlar la agenda, pueden discutir los problemas que deben ser abordados, es decir, existe la posibilidad de definir 
metas y estrategias; sin embargo, no existe injerencia sobre los procesos de toma de decisiones, aunque se permite a la ciudadanía emitir una opinión. La decisión final es adoptada por el gobierno.

\section{ALTO:}

Normativo-delegativo: en este nivel, los ciudadanos sí pueden controlar la agenda, pueden discutir los problemas que deben ser abordados, es decir, existe la posibilidad de definir metas y estrategias; también tienen injerencia sobre los procesos de toma de decisiones, ya que permiten a los ciudadanos un control final del resultado, de la decisión, pero no completo, ya que al gobierno también se le permite participar.

Según esto, la gran mayoría de los mecanismos de participación local en Bogotá, por lo menos de los usados con más frecuencia, tienen una participación muy poco efectiva. Siete de las instancias de participación estudiadas se ubicaron en el nivel medio bajo de efectividad, específicamente como operacional-consultivas.

En ese sentido, podríamos decir que en estas instancias no existe la posibilidad de los ciudadanos de controlar la agenda, pues se les presentan unas estrategias y unos objetivos políticos previamente definidos, sobre los cuales se les permite simplemente emitir opiniones; y que no existe injerencia sobre los procesos de toma de decisiones, porque al final, la decisión es adoptada por el gobierno.

Cinco instancias corresponderían al nivel medio, como estratégico-consultivo: son instancias en las que no existe posibilidad de controlar la agenda pues los objetivos políticos ya están planteados, pero los ciudadanos pueden discutir las estrategias para alcanzarlos; tampoco existe injerencia sobre los procesos de toma de decisiones, pero se permite a la ciudadanía emitir una opinión. Aunque en todo caso, la decisión final es adoptada por el gobierno.

Finalmente, tres instancias más pueden ser clasificadas en un nivel alto de efectividad de la participación, teniendo la posibilidad de controlar la agenda, de definir metas y estrategias; y de tener injerencia sobre los procesos de toma de decisiones, teniendo un control final del resultado, de la decisión, aunque con la participación del gobierno en la decisión. Es el caso de las Asociaciones de usuarios de salud y los Comités de Participación Comunitaria en Salud, y el Consejo Local de Seguridad, los dos primeros con la participación de representantes en las juntas directivas de las empresas, y el segundo con un amplio margen de decisión, aunque es evidente que son instancias en las que los miembros son en su mayoría representantes del sector gobierno, pero cabe destacar que los miembros que asisten en representación de la ciudadanía comparten con los representantes del gobierno la discrecionalidad de la instancia. 


\section{NIVELES DE PARTICIPACIÓN}

En lo que respecta a los niveles de participación según el continuum de Brager y Specht, la clasificación ha sido la siguiente: son mecanismos que podrían tener el nivel asesor el Consejo Territorial de Planeación Distrital y el Consejo Consultivo de Ordenamiento Territorial, el Consejo de Planeación Local, los Consejos Distritales y Locales de Cultura, la Comisión Ambiental Local, los Consejos Locales y Distritales de Política Social, los Comités de Desarrollo y Control Social de los Servicios Públicos, el Comité Local de Emergencias, los Consejos Distritales y Locales de Juventud, el Consejo Local y el Distrital de personas con discapacidad, y las Veedurías Ciudadanas. Son consultivas porque son instancias que -como queda establecido en sus funciones- permiten a la ciudadanía emitir una opinión sobre los temas en cuestión, pero la decisión final siempre es adoptada por el gobierno.

Es así porque se trata de instancias de las que la administración espera propuestas o consejos sobre las propuestas del gobierno, y este solo modificará el plan si hay motivos muy convincentes que lo justifiquen. Sin embargo, no se trata de instancias que puedan tomar decisiones por sí mismas.

Por otro lado, las Asociaciones de Usuarios de Salud y los Comités de Participación Comunitaria en Salud, y los Consejos Locales de Seguridad, podrían tener un nivel de participación en el que se ejerce control, pues son instancias en las que la comunidad, en conjunto con la administración, identifican uno o varios problemas, y en conjunto toman las decisiones sobre objetivos y medios; aquí no se hace solo con la tutela de la administración, sino en conjunto con la administración, pues la conformación de las instancias es mixta.

Así, teniendo en cuenta el continuum de participación de Brager y Specht (1973), de las quince instancias estudiadas, todas corresponden al nivel elevado - de los cuales doce son en el nivel de órgano asesor, y tres en el de ejercicio de control.

En la tabla 3, se puede ver la clasificación de las instancias a través del Continuum de participación ciudadana de Brager y Specht (1973). En ella se observa cómo todas las instancias, aunque se encuentran en el nivel elevado de participación, se limitan a un nivel meramente asesor, en el cual, cómo nos dicen los autores, la organización presenta un plan e invita al público a aportar propuestas/consejos, y lo modificará únicamente si hay motivos muy convincentes que lo justifican, es decir que la decisión final es exclusivamente del gobierno.

Las Asociaciones de Usuarios de Salud, los Comités de Participación Comunitaria en Salud, y el Consejo Local de Seguridad son instancias que corresponderían a un nivel en el que se ejerce control, es decir que pueden realmente injerir en la toma de decisiones al hacer parte de las juntas directivas de las empresas prestadoras de servicios. Estas instancias, aunque limitadas por una presencia mayoritaria de presencia de funcionarios del gobierno, son dentro de las instancias de participación las que mayor poder de decisión tienen dada esta particularidad. 
Tabla 3: Instancias de Participación Local en Bogotá en el Continuum de participación ciudadana de Brager y Specht (1973).

\begin{tabular}{|c|c|c|}
\hline Grado/Nivel & Instancia de Participación local en Bogotá & $\begin{array}{c}\text { Rol/actividad } \\
\text { participante }\end{array}$ \\
\hline \multirow[t]{4}{*}{ Elevado } & $\begin{array}{l}\text { Asociaciones de usuarios de salud } \\
\text { Comités de Participación Comunitaria en Salud } \\
\text { Consejo Local de Seguridad }\end{array}$ & Ejerce Control \\
\hline & & $\begin{array}{l}\text { Ejerce Control } \\
\text { por Delegación }\end{array}$ \\
\hline & & $\begin{array}{l}\text { Planificación } \\
\text { Conjunta }\end{array}$ \\
\hline & $\begin{array}{l}\text { Consejo Territorial de Planeación Distrital y Consejo Con- } \\
\text { sultivo de Ordenamiento Territorial } \\
\text { Consejo de Planeación Local } \\
\text { Consejos Distritales y Locales de Cultura } \\
\text { Comisión Ambiental Local } \\
\text { Consejos Locales de Política Social } \\
\text { Consejos Distritales de Política Social } \\
\text { Comités de Desarrollo y Control Social de los SP } \\
\text { Comité Local de Emergencias } \\
\text { Consejos Distritales y Locales de Juventud } \\
\text { Consejo Local de personas con discapacidad } \\
\text { Consejo Distrital de Personas con Discapacidad } \\
\text { Veedurías Ciudadanas }\end{array}$ & Asesor \\
\hline Bajo & & Consulta \\
\hline Nulo & & $\begin{array}{l}\text { Es receptor de } \\
\text { Información }\end{array}$ \\
\hline
\end{tabular}

Fuente: Elaboración Propia

\section{CONCLUSIONES}

El análisis de las instancias de participación local más usadas en la ciudad de Bogotá a la luz de las herramientas teóricas de Stewart (2007) y Brager y Specht (1973), señala una problemática que no es nueva ni ha sido ajena a los análisis que otros autores han hecho sobre la participación 
en Bogotá (Hernandez, 2010; Velazquez \& Gonzalez, 2003), que las instancias de participación de la ciudad se caracterizan porque los ciudadanos tienen un mínimo control o injerencia sobre las decisiones que se toman. O que en la mayoría de los casos la efectividad de la participación es baja en las diferentes instancias de participación de la ciudad, o media baja como lo definimos aquí, con unos niveles meramente consultivos y asesores.

Esto es problemático en la medida en que, si bien es cierto que la participación también se ejerce a través del control, como es el caso de las veedurías ciudadanas, estas instancias no permiten la realización del ejercicio de la participación de los ciudadanos entendida como verdadera intervención, como nos plantearon los primeros teóricos de la democracia participativa; estos mecanismos no reflejan un verdadero control sobre los procesos de toma de decisiones, en términos de Brager y Specht (2007).

Se convierten en meras instancias legitimadoras de las decisiones de las administraciones locales, y lo que es peor, pueden generar la desilusión y la decepción de los ciudadanos frente a la participación, al ver frustradas sus expectativas sobre lo que significa participar. Para los ciudadanos la participación significa no solo expresarse y ser escuchados, sino también poder resolver sus problemas, proponer soluciones, gestionar sus intereses e incidir en la toma de decisiones (Fundación Foro Nacional por Colombia, 2009). En este sentido, no poder participar en la definición de agendas, o de forma permanente en los procesos de toma de decisiones, resta efectividad a la participación de los ciudadanos, y los puede desencantar frente a las ventajas de la participación.

Esto finalmente nos lleva a que todos perdamos en el juego de la participación: la administración en la medida en que pierde el apoyo de la ciudadanía, y la ciudadanía misma que no ve resueltos los problemas que quisiera solucionar.

\section{BIBLIOGRAFÍA}

- $\quad$ Acuerdo 033 de 2001 del Concejo de Bogotá

- Acuerdo 12 de 1994 del Concejo de Bogotá

- $\quad$ Acuerdo 13 de 2000 del Concejo de Bogotá

- $\quad$ Acuerdo 137 de 2004 del Concejo de Bogotá

- Acuerdo 142 de 2005 del Concejo de Bogotá

- $\quad$ Acuerdo 21 de 2001 del Concejo de Bogotá 
- $\quad$ Acuerdo 22 de 1999 del Concejo de Bogotá

- $\quad$ Arnstein, S. (1969). A ladder of citizen participation. Journal of the American Institute of Planners, 35 (4), 216-224.

- Baños, J. (2006). Teorías de la Democracia: Debates actuales. Andamios: revista de investigación social, 4, 35-58.

- Benito S. (s.f.). República Dominicana, Elecciones Congresuales (1978-2010): evolución de los principales indicadores. Recuperado el 22 de junio de 2012, del sitio: http:// americo.usal.es/oir/opal/elecciones/Elecc_RD_2010_Benito.pdf.

- Bobbio, Norberto (2010). El futuro de la democracia. México: Fondo de Cultura Económica.

- $\quad$ Brager, G. y H. Specht (1973). Community Organizing. Nueva York: Columbia University Press.

- $\quad$ Collier, D. \& Levitksky, S. (1996). Democracy with adjectives: conceptual innovation in comparative research. Kelogg Institute, Working Paper, 230. En Revista Venezolana de Economía y Ciencias Sociales, Caracas, vol. 4 .

- Decreto 064 de 2006 de la Alcaldía Mayor de Bogotá

- Decreto 093 de 2004 de la Alcaldía Mayor de Bogotá

- Decreto 1757 de 1994 de la Alcaldía Mayor de Bogotá

- Decreto 221 de 2002 de la Alcaldía Mayor de Bogotá

- Decreto 332 de 2004 de la Alcaldía Mayor de Bogotá

- Decreto 460 de 2008 de la Alcaldía Mayor de Bogotá

- Decreto 575 de 2011 de la Alcaldía Mayor de Bogotá

- Decreto 625 de 207 de la Alcaldía Mayor de Bogotá

- Decreto 627 de 2007 de la Alcaldía Mayor de Bogotá

- Decreto 665 de 2000 de la Alcaldía Mayor de Bogotá

- Decreto 697 de 1993 de la Alcaldía Mayor de Bogotá 
- Fundación Foro Nacional por Colombia - IDPAC (2009). ¿Cómo participa Bogotá? Bogotá: Foro Nacional por Colombia - IDPAC.

- Hambleton, S. y Hoggett, P. (1994). A framework for understanding area-based desentralisation, Local Goverment. Policy Marketing, 20 (4), 5-12.

- Held, D. (1991). Modelos de Democracia. Madrid: Alianza Editorial.

- Hernández, A. (2010). La participación ciudadana en Bogotá, 1990-2010. Colombia Internacional, 71, 85-107.

- Macpherson, C.B. (2003). La democracia liberal y su época. Madrid: Alianza Editorial.

- Mainwaring, S. y Bejarano, A. (2006). Crisis of Democratic Representation in the Andes. Stanford University Press.

- Ozbekhan, H. (1969). Toward a General Theory of Planning. In Perspectives of planning: Proceedings of the OECD Working Symposium of Long-Range Forecasting and Planning, Bellagio, Italy, edited by Erich Jantsch, 45 - 155. Paris: Organization for Economic Cooperation and Development.

- Pateman, C. (1970). Participation and Democratic Theory. Cambridge: Cambridge University Press.

- Poulantzas, Nicos (1987). Estado, poder y socialismo. México: Siglo XXI.

- Sartori, G. (1994). ¿Qué es la Democracia? Bogotá: Altamir Ediciones.

- Schumpeter, J. (1988). Capitalismo, socialismo y democracia, 2 tomos. Barcelona: Ediciones Orbis.

- Shand, D. y Arnberg, M. (1996). Backgroung Paper in Responsive Government: Service Quality Initiatives. Paris: OECDE,.

- Stewart, K. (2007). Write the rules and win: Understanding Citizen Participation Game Dynamics. Public Administration Review. 1067-1076.

- Velásquez C., y González, E. (2003). ¿Qué ha pasado con la participación ciudadana en Colombia? Bogotá: Fundación Corona.

- Vergara, J. (1998). Teorías democráticas participativas: un análisis crítico. Revista Venezolana de Economía y Ciencias Sociales, 4 (2-3), 155-180. 